\title{
Extending Computational Thinking Activities
}

\author{
Zsuzsa PLUHÁR
}

Eötvös Loránd University, Faculty of Informatics

Budapest, Hungary

e-mail:pluharzs@inf.elte.hu

\begin{abstract}
This report presents the newest extending activity idea, a challenge game of the Hungarian Bebras initiative. The goal of extension is to create unplugged computational thinking activities based on the Hungarian Bebras competition. The target group of this challenge game is flexible, and it could be used in the motivating phase of CT education, and as a first step in Computer Science education.
\end{abstract}

Keywords: Bebras, Hungarian Bebras initiative, computational thinking, unplugged activities.

\section{Introduction - The Hungarian Bebras Initiative}

\subsection{Bebras Initiative}

As Dagienè and Futschek (2008, 2012) summarized Bebras ("beaver") initiative is an "informatics education community-building model" to motivate school students in the topic of Computer Science (CS) and computational thinking (CT). It works basically as an international informatics challenge and it is organized in more than 40 countries all over the world. It renewes our thinking about ICT, ICT education and thinking itself.

The initiative is based on a competition where we use "Bebras tasks". They are short, motivating exercises that can be solved in 3 minutes, using thinking skills in the field of computer science, but they don't require previous knowledge in that.

\subsection{Bebras in Hungary}

Hungary started to work in the Bebras initiative in 2010. Besides the main Bebras goals, the Hungarian organizers have country-specific goals, such as (1) showing how big, interesting and colorful the CS world is; (2) motivating children to be open to CS, problem 


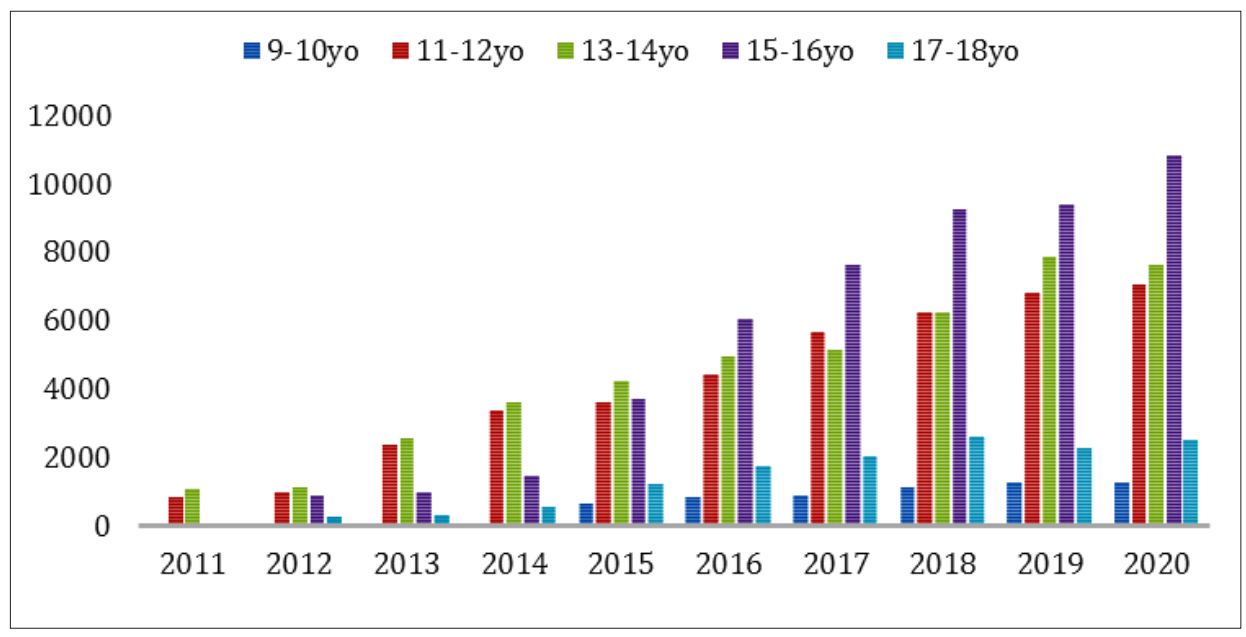

Fig. 1. The number of participants in the Hungarian Bebras challenge 2011-2020.

solving and thinking; (3) helping teachers make informatics education more colorful and understandable; (4) giving ideas to teachers for school and after-school activities.

The main basis of the initiative is the competition, the number of participants (Fig. 1) of which is growing continuously since it has started (Pluhár and Gellér, 2018; Pluhár, 2012).

Last year more than 29thousand students of ages 8-18 tested their knowledge in computational thinking.

\section{Extending the Competition}

In the Hungarian public education, only a small amount of Informatics is found, and the subject mostly focuses on how to use IT systems and software tools. Programming gets less emphasis. Project-based solutions can be used not only in classes but in after school activities, project weeks or days, school days, and summer camp activities.

To acheve the main aims of the Hungarian Bebras we need to extend the challenge and using unplugged, project-based activities.

In addition, the Faculty of Informatics at Eötvös Loránd University has courses where using activities to present and teach $\mathrm{CT}$ principles could be helpful. Bebras unplugged activities are applied not only in teacher education but also in the preliminary year of the international Computer Science BSc program (Pluhár and Torma, 2019).

The basic expandings use cards (Dagienè et al., 2017) or small sheets with text and pictures. Creating project based-challenges should make use of several extended tasks, activities in a pack. 


\subsection{Aims for Basis}

Our basic aims creating a pack are:

- The used tasks need to be funny, motivating and need to include as so many topics in CS as possible.

- The extension-activity needs to have a meaning and should be helpful to solve the problem.

- Each activity needs to be a physical activity: doing something with one's hands or body.

- The activities in a challenge-pack need to be varied and be motivating to solve.

- The tasks need to have the same attributes as in the basic challenge: participants don't need to have pervious knowledge to solve them, tasks can be solved in a few minutes, they need to be unambiguous, interesting, ...

- The ideas can be changed: tasks can be used in modified order, it will be no problem if a task is removed or changed to another one.

- A teacher can prepare the used tools in the school, no need to buy big, expensive things. The cost should be low.

- The challenge is usable for several ages. The task contains guidelines to the solution that can be used by the coordinators.

- The game can be played by students and student-groups as families.

\subsection{Pilot}

The first, pilot version was a pirate treasure game.

I prepared a treasure box with a padlock and 4 small Bebras tasks where participants had a number as the solution. If they added up the numbers they had the code to open the padlock.

I used the following tasks: Pirates (2015-IS-07), Quatris (2018-HU-04), Caesar coding (2017-CH-04b) and Lisas (2014-DE-04).

The main texts and problems were printed. I used printed and laminated cards and code wheels. The Pirates was used as a board game: I prepared a board and the pirate and the policeman were the game figures.

We tested the treasure game in university open days, Researchers' Nights, and on the event "Street of the Future". Our testers were between 6 and 70 years old. The treasures were small promotion gifts. The feedback was positive, and the fun-factor was always higher when a group tried to open the box. They could discuss the problem.

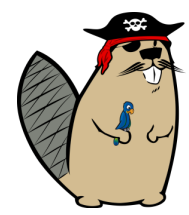




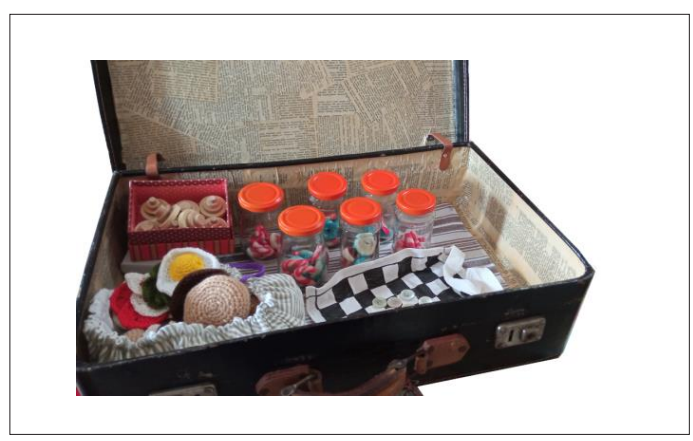

Fig. 2. The suitcase with activity tools.

\section{The Unplugged Bebras Challenge Game}

After the pilot treasure box project and small projects in the topic of escape games with Bebras tasks, I started to prepare a challenge game with guidelines.

A prepared suitcase contains the used tools with printed and laminated instructions and guidelines. The expanded tools are created as a DIY-project: the teachers (and students) themselves can prepare their own versions.

The basic challenge game is defined with 12 stations (activities), but in the pack, I prepared 15 tasks that can be used in different orders. We started developing more new activities that can be put into the suitcase (Fig. 2) and thus renew the game.

The students can participate in groups using a check-sheet where they can collect stamps and points. The game can be played in several versions: the collected points can depend on the rate of the help of the coordinator, the used time of solving the tasks, or the groups can get the stamp regardless of the time and help.

\subsection{Activities}

Each station has an activity that can be solved in a maximum of 10 minutes with support. Each station needs to have a coordinator who readies the station, gives small instructions and help, and resets the original state when a group leaves. The coordinators can tell stories about the task, its connections to CS and other disciplines or to real life.

The prepared guidelines of activities contain:

- The original state of the activity defined for age groups.

- Helping questions, instructions defined for age groups.

- Interesting facts in the topic of CS and connections with other disciplines or the real life.

- Ideas for variations with comments. 


\subsubsection{Example Activity 1-2018-CZ-08c, Word Chain}

The computer science basis of this task is the generalized geography theorem. The original task asks for the longest word chan in a given graph.

This task has two parts in the activity. The first in our version is the same as the original task for the joungest two age groups. Other participants can play the game with words: they have a graph and words (names of cities) and they need to place the words into the graph based on the rules of the original game.

The second part is to write words in a given graph or to prepare their own game: create a graph with words and play.

In this activity the extension is a printed and laminated graph and the cut-out words. This is the easiest way of creating an activity - like a drag\&drop application without an IT tool.

There are some activities where I supplemented the laminated papers with magnets, magnet boards or blutack, paper fasteners. In the case of board games the boards can be printed and the paws can be created manually.

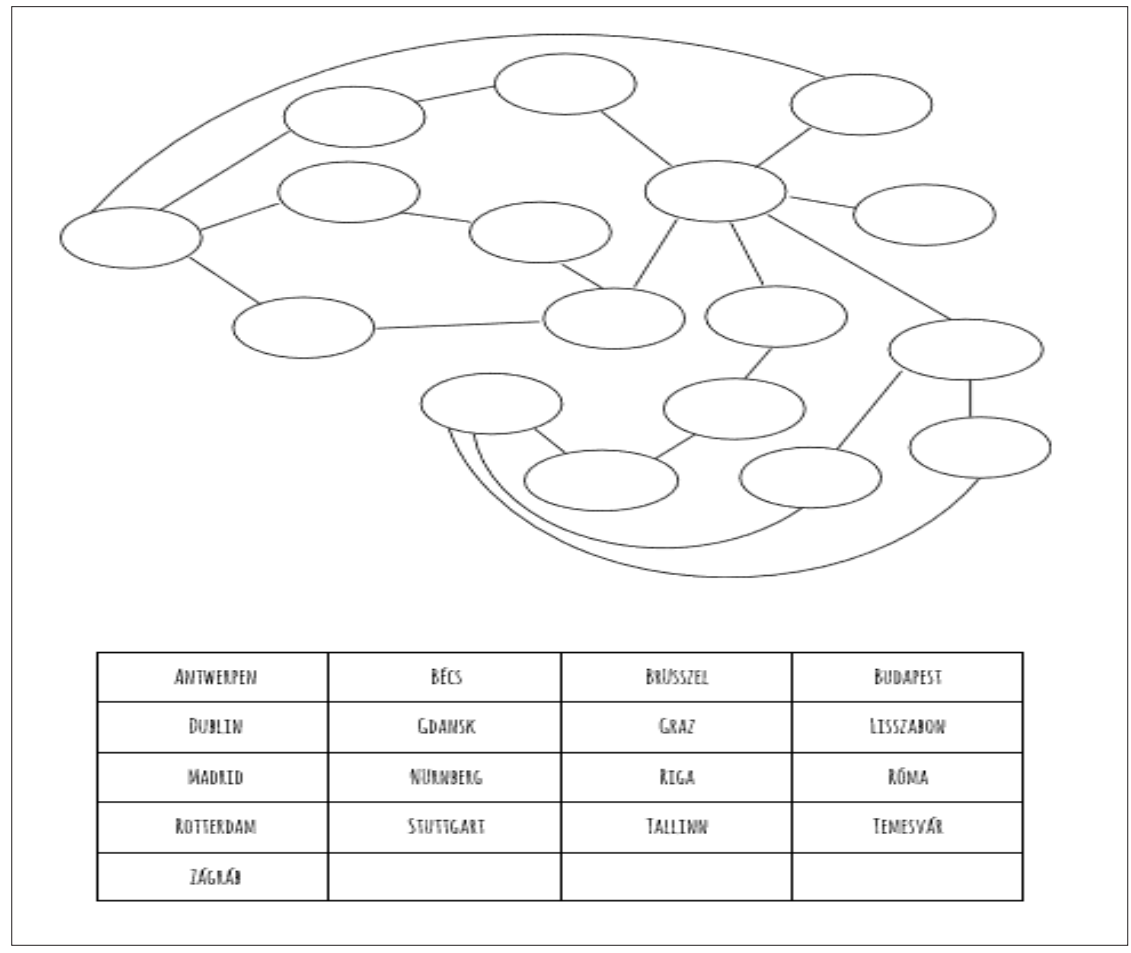

Fig. 3. The template sheet to print, laminate and cut for the task 2018-CZ-08c. 


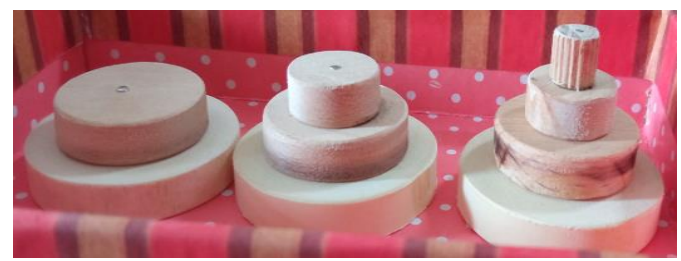

Fig. 4. The wooden disks used in task 2020-CH-04.

\subsubsection{Example Activity 2 - 2020-CH-04, Sudoku}

The original task is a combination of the sudoku and the skyscrapers. The size of the board and the given information (how many trees can be seen from a given position) define the levels for age groups. We prepared variations for the sudoku only - there are some trees on the board and participants/players need to place the others, or all the trees are on the board, and the players need to change their position to correct the situation based on the rules.

The basic board can be printed or cut from color paper. We used $4 \times 4 \mathrm{~cm}$ squares and wooden disks with different diameters placed on each other (Fig. 4).

For some activities we applied plasticine, crochet toys, yars and buttons.

The last planned activity is based on logic: the participants need to open metal mechanical puzzles, some of them were designed and created by my father.

\section{Conclusion}

The main aim of the Hungarian Bebras initative is the motivation. Both teachers and students are open to use new methods and ideas but they should be supported with more ideas and complex solutions.

After the testing phase we would like to prepare two versions from this challengesuitcase: the first can be downloaded, and schools can create their own tools for activities. The second will be a suitcase that schools can buy and use during school activity days, project weeks or in after school events. This will be open for the Bebras community.

I would like to thank to all members of the International Bebras Community and give special thanks to the D-A-CH (Germany, Austria and Switzerland) members to not only help us prepare wonderful tasks but also to give ideas, help and support to organize the Hungarian Bebras Contests every year, and my father $(\dagger)$ who supported and guided my ideas to solutions. 


\section{References}

Dagienė, V., Futschek, G. (2008). Bebras International Contest on Informatics and Computer Literacy: Criteria for Good Tasks. In: R.T. Mittermeir, M.M. Syslo (Eds.), Informatics Education - Supporting Computational Thinking. Lect. Notes in Computer Science. Vol. 5090, Springer, 19-30.

Dagienè, V., Futschek, G. (2012). Knowledge construction in the Bebras problem solv-ing contest. Conference: Constructionism, 2012.

Pluhár, Z., Gellér, B. (2018). International Informatic Challenge in Hungary. In: Teaching and Learning in a Digital World : Proceedings of the 20th International Conference on Interactive Collaborative Learning. Berlin, Germany: Springer, pp. 425-435.

Pluhár, Zs. (2012). Bit HÓDítás. In: Ollé János (ed.) 4. Oktatás-Informatikai Konferencia: Tanulmánykötet. Budapest. ELTE Eötvös Kiadó, 187-191.

Pluhár, Zs., Torma, H. (2019). Introduction to Computational Thinking for university students. In: Lecture Notes in Computer Science, 11913. pp. 200-209, 10 p.

Dagienė, V., Futschek, G., Koivisto, J., Stupurienè, G. (2017). The card game of Bebras-like tasks for introducing informatics concepts. In: ISSEP 2017 Online Proceedings. Helsinki, 13.11.2017-15.11.2017.

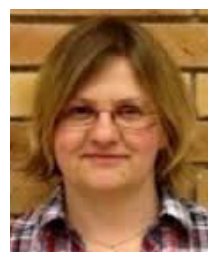

Zs. Pluhár is an assistant lecturer of the Faculty of Informatics at Eötvös Loránd University, Budapest, Hungary. She is a member of the T@T (Technology Enhanced Learning) Lab and works mostly in teacher education. She is the head of the Professional Community of Public Education at John von Neumann Computer Society. Her research fields are computational thinking, education of robotics and STE(A)M. Since 2011 she has been organizing the Bebras informatics contest in Hungary. 
